\title{
PHYTOCHEMICAL ANALYSIS AND IN VITRO FREE RADICAL SCAVENGING ACTIVITY OF SUCCESSIVE EXTRACTS OF ALYSICARPUS VAGINALIS VAR. NUMMULARIFOLIUS (DC.) MIQ
}

\author{
SUSAN KURIAN*, LEENAMMA JOSEPH, JOSEKUMAR V. S. \\ Department of Zoology, Mar Ivanios College (Autonomous), Thiruvananthapuram, Kerala, India \\ Email: susankurianmic@gmail.com
}

Received: 27 Dec 2016 Revised and Accepted: 19 Jun 2017

\begin{abstract}
Objective: The present study was carried to evaluate free radical scavenging activity and phytochemical analysis of successive extraction with hexane (AVH), ethyl acetate (AVE) and methanol (AVM) of Alysicarpus vaginalis var. nummularifolius (DC.) MIQ., a herb used in home remedies.

Methods: The entire plant was dried and powdered, successively extracted (soxhlet apparatus) and concentrated using rotary vacuum evaporator. The extracts were quantitatively analyzed for phytochemicals like total phenolic, flavonoids, alkaloids and carbohydrates following standard methods. The free radical scavenging activity was evaluated with DPPH (1,1-diphenyl-2-picrylhydrazyl), nitric oxide radical and hydrogen peroxide scavenging reactions.

Results: The quantitative phytochemical studies of the crude extracts showed that AVM extract with highest phenolic, flavonoid, alkaloid and carbohydrate content which is followed by AVE and AVH. The IC ${ }_{50}$ values of AVH, AVE and AVM for scavenging DPPH, nitric oxide and hydrogen peroxide were $589.21 \pm 0.09 \mu \mathrm{g} / \mathrm{ml}, 254.65 \pm 0.08 \mu \mathrm{g} / \mathrm{ml}$ and $261.40 \pm 0.08 \mu \mathrm{g} / \mathrm{ml} ; 533.81 \pm 0.09 \mu \mathrm{g} / \mathrm{ml}, 362.07 \pm 0.09 \mu \mathrm{g} / \mathrm{ml}$ and $456.36 \pm 0.08 \mu / \mathrm{ml} ;$
\end{abstract} $464.66 \pm 0.08 \mu \mathrm{g} / \mathrm{ml}, 380.29 \pm 0.08 \mu \mathrm{g} / \mathrm{ml}$ and $367.6 \pm 0.08 \mu \mathrm{g} / \mathrm{ml}$ respectively.

Conclusion: The present study revealed that AVM extracts having high polyphenolic compounds when compared with AVE and AVH. The free radical scavenging reaction was greater in ethyl acetate and methanol extracts. This suggests that due to the high antioxidant reactions, these extracts can be useful for the treatment of oxidative stress-related diseases.

Keywords: Alysicarpus vaginalis var. nummularifolius (DC), Phytochemical analysis, Antioxidant, Free radical, Phenolic

(C) 2017 The Authors. Published by Innovare Academic Sciences Pvt Ltd. This is an open access article under the CC BY license (http://creativecommons.org/licenses/by/4.0/) DOI: http://dx.doi.org/10.22159/ijpps.2017v9i6.16814

\section{INTRODUCTION}

The basis of traditional herbal medicine practiced in the past and also in the present are due to the bioactivity of phytochemicals [1]. Plants are endowed with various phytochemical molecules such as vitamins, terpenoids, phenolic acids, lignins, tannins, flavonoids, quinones, coumarins, alkaloids, amines and other metabolites, which are rich in antioxidant activity $[2,3]$. The free radicals have been implicated in causing many diseases. Reactive oxygen species (ROS) cause tissue injury through covalent binding and lipid peroxidation [4] which contribute the pathogenesis of many diseases [5]. Antioxidants scavenge the free radicals and thereby terminate the chain reaction that can damage cells. Antioxidants present in plant help in the stimulation of cellular defence system and oxidative damage [6]. Studies have shown that many of these antioxidant compounds possess anti-inflammatory, antiatherosclerotic, antitumor, antimutagenic, anticarcinogenic, antibacterial, and antiviral activities $[7,8]$.

Alysicarpus vaginalis var. nummularifolius (DC.) Miq. Commonly known as Alyce clover, belongs to the family: Fabaceae (Leguminosae). Traditionally it is used for the treatment of many diseases like jaundice, pulmonary diseases, diabetes and leprosy. The antioxidant and antiproliferative activity of ethanolic extract of $A$. vaginalis was identified [9]. The phytochemical analysis and free radical scavenging activity of successive extraction of $A$. vaginalis var. numularifolius has not yet studied. Hence an attempt has taken to analyze the phytochemical constituents and evaluate the free radical scavenging activity of a successive extract of hexane $(\mathrm{AVH})$, ethyl acetate (AVE) and methanol (AVM) of A. vaginalis.

\section{MATERIALS AND METHODS}

\section{Chemicals and reagents}

Hexane, ethyl acetate, methanol, dimethylsulfoxide (DMSO), Folinciocalteau reagent, hydrochloric acid, Dragendorff reagent, sodium carbonate, gallic acid, aluminum chloride, potassium acetate, quercetin, anthrone, glucose, hydrogen peroxide, sulphanilamide, phosphoric acid,
N-ethylene diamine dihydrochloride, 1,1-diphenyl-2-picrylhydrazyl (DPPH), were purchased from Himedia, Chemical, India. All the chemicals and solvents used were of standard analytical grades.

\section{Collection and identification of plant material}

Alysicarpus vaginalis var. nummularifolius (DC.) Miq. was collected from Nalanchira, Thiruvananthapuram, Kerala, India. The plant materials were identified and authenticated byDr. G. Valsaladevi, Curator, Department of Botany, University of Kerala, Kariavattom, Thiruvananthapuram, Kerala. The voucher specimen has been deposited in the Herbarium of Department of Botany, the University of Kerala with voucher no KUBH-5928 for future reference.

\section{Extraction procedure}

The entire plant was used for extraction. Collected plant was washed, shade dried and powdered in an electric grinder. The powdered material was successively extracted in soxhlet apparatus with hexane (AVH), ethyl acetate (AVE) and methanol (AVM) in the order of their increasing polarity until it becomes colourless using the standard protocol [10]. The solvents were then removed using rotary vacuum evaporator and stored in the refrigerator for further analysis.

\section{Quantitative estimation of phytochemicals}

\section{Estimation of total phenolic content (TPC)}

Total phenolic content of the extracts was measured using FolinCiocalteau spectrometric method [11]. Test samples of different concentration (10-500 $\mu \mathrm{g})$ dissolved in $1 \%$ DMSO were mixed with $1 \mathrm{ml} 95 \%$ ethanol. $0.25 \mathrm{ml}$ of Folin-ciocalteau was added to each test tube. After $2 \mathrm{~min}, 0.75 \mathrm{ml}$ of $20 \%$ sodium carbonate was added and the volume was made up to $5 \mathrm{ml}$ with distilled water. The mixture was vortexed, left for $2 \mathrm{~h}$ and the absorbance was measured at $700 \mathrm{~nm}$. A standard curve was plotted using 10-500 $\mu \mathrm{g}$ of gallic acid in $95 \%$ ethanol. Total phenolic content was expressed as mg of gallic acid equivalent (GAE)/g of leaf extract. 


\section{Estimation of total flavonoid content}

Flavanoid content was determined by aluminium-chloride colorimetric method [12]. The method is based on the formation of the acid stable, flavanoid-aluminium complex. $0.5 \mathrm{ml}$ of each extract in ethanol $(10$ $\mathrm{mg} / \mathrm{ml}$ ) was mixed with $1.5 \mathrm{ml}$ methanol, $0.1 \mathrm{ml}$ aluminium chloride (10 $\%), 0.1 \mathrm{ml}$ potassium acetate solution and $2.8 \mathrm{ml}$ distilled water were added sequentially and mixed well. A blank sample was prepared in a similar way by replacing $\mathrm{AlCl} 2$ with distilled water. The test solution was vigorously shaken. Absorbance was recorded at $415 \mathrm{~nm}$ after $40 \mathrm{~min}$ of incubation. A standard calibration plot was generated at $415 \mathrm{~nm}$ using known concentrations of quercetin. The concentrations of flavonoid in the test samples were calculated from the calibration plot and expressed as mg quercetin equivalent/g of sample. All the determinations were carried out in triplicate.

\section{Estimation of total alkaloids}

The alkaloids estimation was performed by the spectrophotometric method of dragmen doffs reagent as it was described by Sreevidya and Mehrotra, 2003 [13]. $10 \mathrm{mg}$ amount of each crude extract was centrifuged over $10 \mathrm{~min}$ (3000 rpm) to remove residual suspended particles. $0.5 \mathrm{ml}$ extract was mixed with $1 \mathrm{ml}$ of $0.1 \mathrm{~N} \mathrm{HCl} .0 .25 \mathrm{ml}$ of dragendroff's reagent was added and the precipitate formed was centrifuged. The precipitate was further washed with $0.25 \mathrm{ml}$ of ethanol. The filtrate was discarded and the residue was then treated with $0.25 \mathrm{ml}$ of $1 \%$ disodium solution. The brownish black precipitate formed was the centrifuged ( $5 \mathrm{~min}, 3000 \mathrm{rpm}$ ). This residue was dissolved in $0.2 \mathrm{ml}$ of concentrated nitric acid and 0.1 $\mathrm{ml}$ was then pipette out and mixed with $0.5 \mathrm{ml}$ of $3 \%$ thiourea solution. The absorbance was measured at $435 \mathrm{~nm}$ against a blank containing nitric acid and thiourea. A standard calibration curve was plotted using 20-100 $\mu \mathrm{g}$ of caffeine. Total alkaloids were expressed as $\mathrm{mg}$ of caffeine equivalent/g of leaf extract.

\section{Estimation of total carbohydrate}

The total carbohydrate content was estimated by Hedge and Hofreiter, 1962[14] anthrone method. The method is based on the formation of hydroxyl methyl furfural in an acidic medium which gives a green coloured product with anthrone having an absorption maximum at $630 \mathrm{~nm} .10 \mathrm{mg}$ of sample was hydrolyzed with $0.5 \mathrm{ml}$ of $2.5 \mathrm{~N} \mathrm{HCl}$ in a boiling water bath for three hours and cooled to room temperature. Neutralized it with sodium carbonate until the effervesces ceases. Made the volume to $10 \mathrm{ml}$ and centrifuged. The supernatant was collected and $1 \mathrm{ml}$ aliquot was taken for analysis. Standards were prepared by taking $0.2-1.0 \mathrm{ml}$ of the working standard (glucose). $1 \mathrm{ml}$ of water served as a blank. All the tubes are made up to $1.0 \mathrm{ml}$ with distilled water. $4.0 \mathrm{ml}$ of anthrone reagent was added, heated for eight minutes in a boiling water bath, cooled rapidly and read the absorbance at $630 \mathrm{~nm}$. A standard curve was plotted using 20-100 $\mu$ g of glucose.

\section{Free radical scavenging assay}

\section{DPPH radical scavenging activity}

Free radical scavenging activity of the extracts of A. vaginalis was measured by the methodology given Brand-Williams et al., 1995 [15] using DPPH (1,1-diphenyl-2-picrylhydrazyl). Dissolve $3 \mathrm{mg}$ of DPPH in $100 \mathrm{ml}$ of $70 \%$ methanol to make a working solution of DPPH. Each extract $(0.5 \mathrm{ml})$ was added to $2.5 \mathrm{ml}$ freshly prepared DPPH solution and mixed vigorously. DPPH solution was reduced from purple to yellow coloured product, diphenyl picryl hydrazine by radical scavenging activity of the extract. The reduction of the DPPH radical was measured by continuous monitoring the decrease in absorbance at $517 \mathrm{~nm}$ until a stable value was obtained. All the experiments were carried out in triplicates. A blank reading was obtained using methanol instead of samples and ascorbic acid was used as the positive control.

Percent inhibition was determined according to the equation:

$\%$ inhibition $=[$ (Absorbance of blank

- Absorbance of sample)

/Absorbance of blank] $\times 100$.

$\mathrm{IC}_{50}$ value (mg extract/ml) was the inhibitory concentration at which DPPH radicals were scavenged by $50 \%$ which was calculated from percentage inhibition.

\section{Nitric oxide radical scavenging assay}

The NO generated from sodium nitroprusside (SNP) was measured by Grieselllosvoy reaction. [16]. Stock solution $(10 \mathrm{mmol})$ of SNP was prepared in phosphate buffer ( $\mathrm{pH}$ 7.4). Different concentration of the extract $(100-500 \mu \mathrm{g} / \mathrm{ml})$ and SNP $(1 \mathrm{mmol})$ in PBS in a final volume of $3 \mathrm{ml}$ were incubated for $2 \mathrm{~h}$ at room temperature. $1 \mathrm{ml}$ of $0.33 \%$ sulphanilamide (in $20 \%$ glacial acetic acid) was added and allowed to stand for $5 \mathrm{~min} .1 \mathrm{ml}$ of $0.1 \%$ naphthyl ethylenediamine was added and the mixture was further incubated for $30 \mathrm{~min}$. Ascorbic acid was used as the reference compound. The colour formed was measured spectrophotometrically at $540 \mathrm{~nm}$ against a blank sample. The percentage inhibition of NO was calculated by comparing with the control.

$$
\begin{aligned}
& \text { Percentage of Nitric Oxide scavenged } \\
& =[(\text { Absorbance of blank } \\
& - \text { Absorbance of sample }) \\
& \text { /Absorbance of blank }] \times 100 .
\end{aligned}
$$

\section{Hydrogen peroxide scavenging assay}

Hydrogen peroxide assayed as described by Ruch et al., 1989 [17] proposed an assay for the determination of antioxidant activity of compounds by their ability to scavenge the oxidant hydrogen peroxide. The reaction mixture contained phosphate buffer (pH-7.4), hydrogen peroxide in phosphate buffer $(40 \mathrm{mmol})$. A solution of hydrogen peroxide $(40 \mathrm{mmol})$ was prepared in phosphate buffer. Plant extracts at the concentration of $10 \mathrm{mg} / 10 \mu \mathrm{l}$ were added to a hydrogen peroxide solution $(0.6 \mathrm{ml}, 40 \mathrm{mmol})$. The total volume was made up to $3 \mathrm{ml}$. The absorbance of the reaction mixture was recorded at $230 \mathrm{~nm}$. The blank solution contained phosphate buffer without

Hydrogen peroxide. The percentage of hydrogen peroxide scavenged by the plant extract was calculated as follows:

Percentage of scavenged $\mathrm{H} 2 \mathrm{O} 2$

$=[$ Absorbance of blank

- Absorbance of sample)

\section{Statistical analysis}

/Absorbance of blank] $\times 100$

The quantitative estimation of the phytochemicals was determined by linear regression analysis method. The $\mathrm{IC}_{50}$ value of free radical scavenging activity was calculated using probit analysis method in SPSS (version 16). Statistical analysis was performed for the free radical scavenging activity by one-way analysis of variance (ANOVA) followed by Duncan's Multiple Rrarnge tests (DMRT) in SPSS. P value $<0.01$ was considered as significant at $1 \%$ level. All the experiments were carried out in triplicate.

\section{RESULTS}

\section{Phytochemical estimation}

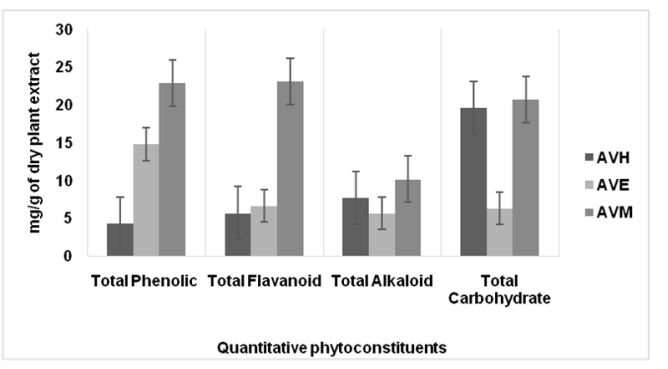

Fig. 1: Quantitative estimation of phytoconstituents of Alysicarpus vaginalis $(\mathrm{n}=3$, values mean $\pm \mathrm{SD})$

The results of quantitative analysis of various phytoconstituents of hexane, ethyl acetate and methanol extracts of $A$. vaginalis are given in fig. 1. The total phenolic content of AVH, AVE and AVM were estimated as $4.32 \pm 0.15 ; 14.81 \pm 0.81$ and $22.92 \pm 0.17 \mathrm{mg} / \mathrm{g}$ of dry plant extract respectively from the standard curve of gallic acid $(y=0.0256 x+0.475$, $\mathrm{R}^{2}=0.9031$ ). Total flavonoid content was evaluated from the standard 
curve of quercetin $\left(y=0.0001 x+0.011 ; R^{2}=0.988\right)$. Highest flavonoid content was that of AVM with $23.1 \pm 0.089 \mathrm{mg} / \mathrm{g}$ of dry plant extract. The total alkaloid content of AVH, AVE and AVM was identified as $7.72 \pm 0.2 ; 5.66 \pm 0.37$ and $10.19 \pm 0.38 \mathrm{mg} / \mathrm{g}$ of dry plant extract respectively from the standard curve of caffeine $(y=0.0113 x \pm 0.0324$; $\mathrm{R}^{2}=0.9978$ ). Total carbohydrate content was highest in AVM $(20.73 \pm 0.55)$ followed by AVH $(19.6 \pm 0.5)$ and AVE $(6.36 \pm 0.36)$ from the standard curve of glucose $\left(y=0.0012+0.867, \mathrm{R}^{2}=0.9945\right)$.

\section{Free radical scavenging activity}

Free radical scavenging assay is mostly used as an index of antioxidant activity of crude plant extract. Free radical scavenging activity of the crude extracts of $A$. vaginalis was carried out by DPPH, nitric oxide and hydrogen peroxide assays. The free radical scavenging activity was found to be dose-dependent and the results were compared with ascorbic acid, which was used as the standard.

The percentage of DPPH scavenging capacity of the crude extracts of $A$. vaginalis is depicted in the fig. 2 . The $\mathrm{IC}_{50}$ value of $\mathrm{AVH}, \mathrm{AVE}$ and AVM were found to be $589.21 \pm 0.09 \mu \mathrm{g} / \mathrm{ml}, 254.65 \pm 0.08 \mu \mathrm{g} / \mathrm{ml}$ and $261.40 \pm 0.08 \mu \mathrm{g} / \mathrm{ml}$ respectively for DPPH scavenging activity (fig. 3 ).

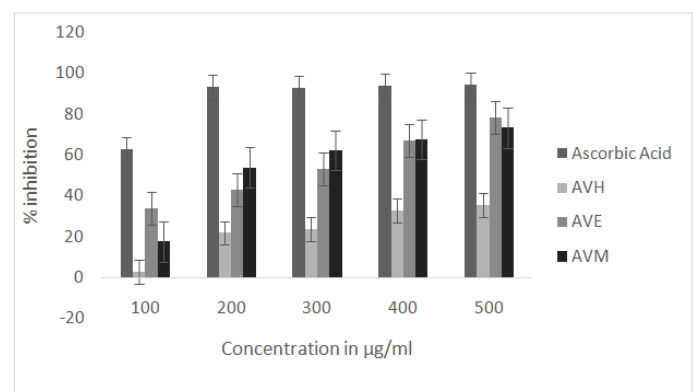

Fig. 2: DPPH radical scavenging activity of different extracts of Alysicarpus vaginalis

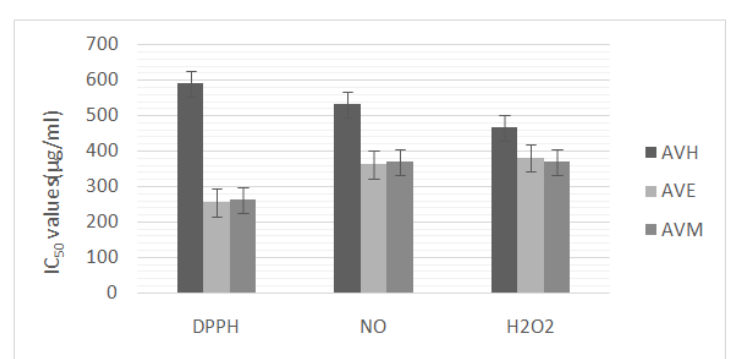

Fig. 3: IC 50 value of free radical scavenging activity of Alysicarpus vaginalis

In the nitric oxide scavenging assay, the crude extract showed a dosedependent effect (fig. 3). The IC $\mathrm{C}_{50}$ value for nitric oxide scavenging activity for AVH, AVE and AVM was found to be $533.81 \pm 0.09 \mu \mathrm{g} / \mathrm{ml}$, $362.07 \pm 0.09 \mu \mathrm{g} / \mathrm{ml}$ and $456.36 \pm 0.08 \mu \mathrm{g} / \mathrm{ml}$ respectively.

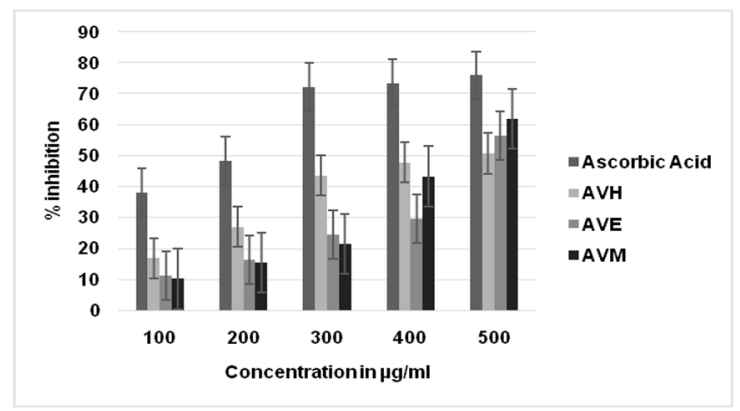

Fig. 4: Nitric oxide radical scavenging activity of different extracts of Alysicarpus vaginalis
The crude extracts of $A$. vaginalis showed a strong hydrogen peroxide scavenging activity (fig. 4). IC 50 value being highest for AVH $(464.66 \pm 0.08 \mu \mathrm{g} / \mathrm{ml})$ followed by AVE $(380.29 \pm 0.08 \mu \mathrm{g} / \mathrm{ml})$ and AVM $(367.6 \pm 0.08 \mu \mathrm{g} / \mathrm{ml})$.

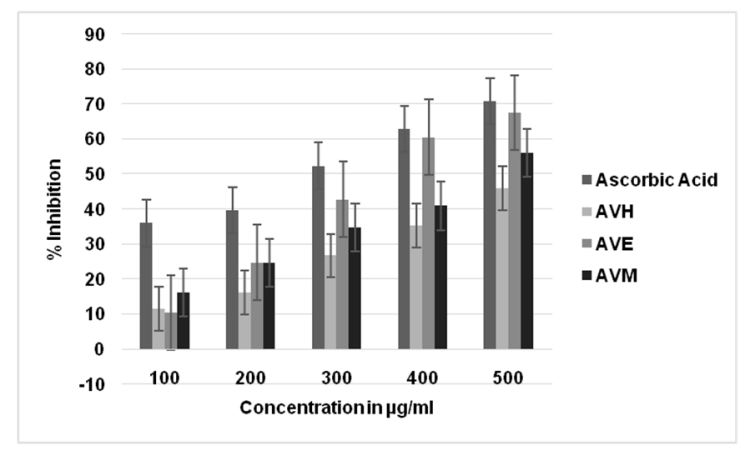

Fig. 5: Hydrogen peroxide radical scavenging activity of different extracts of Alysicarpus vaginalis

\section{DISCUSSION}

Alysicarpus vaginalis var. nummularifolius (DC) is used for the renal calculi treatment in traditional medicine [18]. The root of this plant is also used for various diseases related with kidney and pulmonary [19]. Preliminary phytochemical screening of the plant showed the presence of polyphenols [20]. Antioxidant and antibacterial properties of the ethanolic and aqueous extracts were reported [21]. All these reports reveal that the plant possesses various pharmacological activities.

Literature studies identified that scientific investigation on successive extracts of $A$. vaginalis has not been done. Hence the present study is the first kind of it to report the phytochemical evaluation and free radical scavenging activity of different extracts of $A$. vaginalis.

The findings reveal that methanol extract of the plant possesses the highest quantity of all phytochemicals which was followed by ethyl acetate and hexane extract. Studies show that polar fractions possess the major phytochemicals [22, 23]. Polyphenols are highly present in these plant extracts. They are secondary metabolites which is having antioxidant activity in scavenging of free radicals [24]. The free radical scavenging activity of the plant extracts is clearly established from the present investigation.

Free radicals are constantly generated in the body during the metabolic process. When the production of these free radicals exceeds the antioxidant mechanism in the body, they cause extensive damage to the cells may lead to many degenerative diseases [25]. Antioxidants which are naturally derived counteract the oxidative stress which are induced by various toxicants. In the present study, the antioxidant capacity of the crude extract of the plant was evaluated using DPPH, nitric oxide and hydrogen peroxide free radical scavenging activity assays.

DPPH is a free radical at normal temperature. The colour of methanolic solution of DPPH gives specific absorbance at $517 \mathrm{~nm}$. DPPH is a stable free radical that accepts an electron or hydrogen radical to become a stable molecule [4]. The decrease in absorbance of mixture indicates the radical scavenging activity $[26,27]$.

Nitric oxide is a free radical produced in the mammalian body which is the mediator of many physiological processes [28]. Nitric oxide radical is generated from sodium nitroprusside in the presence of a physiological buffer. Decrease in colour intensity is directly proportional to nitric oxide radical scavenging, which is measured in terms of IC50.

Hydrogen peroxide inactivates some enzymes by oxidation of essential thiols (-SH) groups [29]. Hydrogen peroxide crosses cell membrane and reacts with ferric and copper ions and produce a toxic effect. The extract shows a good hydrogen peroxide scavenging activity. The present study reveals that methanol extract of the plant 
possesses high phenolic content than ethyl acetate and hexane extract. The antioxidant activity is seen high in both methanol and ethyl acetate extracts than the hexane extract. Hence this plant can be identified as a good source of bioactive compounds that are having high pharmacological activity.

\section{CONCLUSION}

From the present study, it can be concluded that methanol extract of A. vaginalis has high polyphenolic components. Methanol and ethyl acetate extracts of the plant show high antioxidant activity than the hexane extract. Further efforts are needed for the isolation and characterization of the bioactive compound and the in vivo studies can reveal the mechanism of the action of these plant extracts.

\section{ACKNOWLEDGEMENT}

The authors wish to thank the Principal, Mar Ivanios College, Thiruvananthapuram, Kerala, for providing the necessary facilities to do the work. The financial support from the University Grand Commission in the form of Teacher Fellowship under the Faculty Development Programme (No. FIP/12 th Plan/KLKE013 TF-08 dt. 09/02/2016) is acknowledged by the first author.

\section{CONFLICT OF INTERESTS}

The authors declare no conflict of interest

\section{REFERENCES}

1. Ugochukwu SC, ArukweUche I, OnuohaIfeanyi. Preliminary phytochemical screening of different solvent extracts of stem bark and roots of Dennetia tripetala G. Baker Asian J Plant Sci Res 2013;3:10-3.

2. Zheng W, Wang SY. Antioxidant activity and phenolic compounds in selected herbs. J Agric Food Chem 2001;49:11:5165-70.

3. Cai YZ, Sun M, Corke H. Antioxidant activity of betalains from plants of the Amaranthaceae. J Agric Food Chem 2003;51: 2288-94.

4. Govidarajan R, Vijaykumar M, Rawat AKS, Mehrotra S. Free radical scavenging potential of Picrrhiza kurrooa Royle ex Benth. Indian J Exp Biol 2003;41:875-9.

5. Halliwell B, Gutteridge JM. The role of free radicals and catalytic metal ions in human disease: an overview. Methods Enzymol 1990;186:1-85.

6. Sonia Sharma, Adarsh Pal Vig. Evaluation of in vitro antioxidant properties of methanol and aqueous extracts of Parkinsonia aculeata L. leaves. Sci World J 2013. http://dx.doi.org/ 10.1155/2013/604865

7. Burkill HM. The useful plants of west tropical Africa. Royal Botanic Gardens Kew 1985;3:9.

8. Saritha B, Brindha P. Review of ethanopharmacognosy of Justicia tranquebariensis L-A traditional siddha drug. Int J Pharm Technol 2013;5:467-74.

9. Rathi MA, Periasamy M, Gopalakrishnan VK. Hepatoprotective activity of Alysicarpus vaginalis against nitrobenzene-induced hepatic damage in rats. South Indian J Biol Sci 2015;1:60-5.

10. Harborne JB. Phytochemical methods. 2nd edition. Chapman and Hall Publications, London, NewYork; 1984. p. 288.

11. Singleton VL, Singleton R Orthofer, Lamuela-Raventos RM. Analysis of total phenols and other oxidation substrates and antioxidants by means of folin-ciocalteu reagent. Methods Enzymol 1999;299:152-78.
12. Mervat MM, Far El, Hanan A, Taie A. Antioxidant activities, total anthocyanins, phenolics and flavonoids contents of some sweet potato genotypes under stress of different concentrations of sucrose and sorbitol. Aust J Basic Appl Sci 2009;3:3609-16.

13. Sreevidya N, Mehrotra S. Spectrophotometric method for estimation of alkaloids precipitable with dragendorff's reagent in plant materials. J AOAC Int 2003;6:86.

14. Hedge JE, Hofreiter BT. Determination of reducing sugars. Methods in carbohydrate chemistry. M. L. Academic Press; New York; 1962. p. 3888-9.

15. Brand-Williams W, Cuvelier ME, Berset CLWT. Use of a free radical method to evaluate antioxidant activity. LWT Food Sci Technol 1995;28:25-30.

16. Garratt Dc. The quantitative analysis of drugs. Japan: Chapman and Hall Ltd. 1964;3:456-8.

17. Ruch RJ, Cheng SJ, Klaunig JE. Prevention of cytotoxicity and inh ibition of intracellularinhibition of intracellular communication by antioxidant catechins isolated from Chinese green tea. Carci nogenesis 1989;10:1003-8.

18. Ediriweera ERHSS. A review on medicinal uses of weeds in Sri Lanka. Trop Agric Res Extension 2007;10:11-6.

19. Burkil HM. Useful plants of west tropical Africa. Vol. 1. A-D. Royal Botanic Gardens, Kew; 1985. p. 960.

20. Rathi MA, Meenakshi P, Guru Kumar D, Arul Raj C, Thirumoorthi L, Gopalakrishnan VK. Potential antioxidant and antiproliferative activities of Alysicarpus vaginalis (L.)DC. J Pharm Res 2010;3:2375-7.

21. Rattanata N, Sakda D, Suthep P. Antioxidant and antibacterial properties of selected Thai weed extract. Asian Pac J Trop Biomed 2014;4:890-5.

22. Anokwuru CP, Anyasor GN, Ajibaye O, Fakoy O, Okebugwa P. Effect of extraction solvents in phenolic, flavonoids and antioxidant activities of three Nigirian medicinal plants. Nat Sci 2011;9:53-61.

23. Kumoroa AC, Hasana M, Singh H. Effect of solvent properties on the soxhlet extraction of diterpenoid lactones from Andrographis paniculata leaves, Sci Asia 2009;35:306-9.

24. Wong SP, Leong LP, Koh JHW. Antioxidant activities of aqueous extracts of selected plants. Food Chem 2006;99:775-83.

25. Sakat S, Juvekar AR, Gambhire MN. In vitro antioxidant and anti-inflamatory activity of methanol extract of Oxalis corniculata Linn. Int J Pharm Pharm Sci 2010;2:146-55.

26. Niyati S Acharya, Jagruti J Patel. Phytochemical evaluation and in vitro antioxidant and anti-inflammatory effects of Clerodendrum serratum roots. Int J Pharm Pharm Sci 2016;8:158-63.

27. Tarun G, Pindi PK. Evaluation of antioxidant potential and antimicrobial activity of successive extracts of Pimpinella tirupatiensis. J Pharm Res 2013;7:817-22.

28. Choudhary GP. Free radical scavenging activity of seeds of Trigonella. J Nat Rem 2006;6:99-102.

29. Begum VH. In vitro antioxidant activity of Asparagus racemosus root. Pharmacogn Mag 2007;3:26-33.

\section{How to cite this article}

- $\quad$ Susan Kurian, Leenamma Joseph, Josekumar VS. Phytochemical analysis and in vitro free radical scavenging activity of successive extracts of Alysicarpus vaginalis var. nummularifolius (DC.) miq. Int $\mathrm{J}$ Pharm Pharm Sci 2017;9(6):231-234. 